\title{
How to Prevent Nasal Obstruction After Rhino Septoplasty. Could A Routine Turbinate Reduction Improve the Outcomes in Quality of Life of Patients?
}

\author{
Bianca H de Moura* \\ Department of Otolaryngology and Head and Neck Surgery, Hospital de Clinicals de Porto Alegre (HCPA), Brazil
}

*Corresponding author: Bianca H de Moura, Department of Otolaryngology and Head and Neck Surgery, Universidade Federal do Rio Grande do Sul, Hospital de Clinicals de Porto Alegre (HCPA), Brazil

\begin{abstract}
The Objective of this article is to Review current literature about performing a turbinectomy associated with Rhinoseptoplasty. Three clinical trials with level one of evidence about the issue have been published recently. All of them selected patients with nasal obstruction who were submitted to Rhinoseptoplasty. The NOSE scale to measure quality of life in these patients was used. Other tools of objective measurement as Acoustic rhinometry and rhinomanometry or subjective scales, Snot-20 WHOQOl and ROE were also explored. Each study used a different technique for turbinate reduction. All of the three found the same results discussed below. To review the scientific evidences of these articles can bring new outlook about this controversial topic.
\end{abstract}

Abbreviations: QOL: Quality of Life; NOSE: Nasal Obstruction Symptom Evaluation; ROE: Rhinoplasty Outcome Evaluation

\section{Mini- Review}

Rhinoplasty is often performed to restore nasal function and form. The development or maintenance of nasal obstruction after rhinoplasty is a complication that negatively affects quality of life (QOL), and priority should be given to prevention strategies [1]. However, the available surgical techniques to prevent this obstruction have been empirically developed and are often used based on the surgeon's preference rather than on objective criteria. Currently, strategies like spreaders grafts, support grafts, reconstruction or repositioning cartilages and even a good septoplasty are used to enlarge the nasal valve [2-6]. Another technique widely used is the Reduction of the inferior turbinate [3,7-9]. Otherwise, an established technique to reduce turbinate with hypertrophy is still debatable [10-13]. Reviews pointed that research in this field appears to be driven by technological advancement rather than by establishment of patients' benefit. Partly, because of the lack of properly conducted randomized controlled trial with long term results. Some articles even question the efficacy of this procedure in cases of nasal obstruction explained for other reasons rather than turbinate hypertrophy isolated [14]. A Recent clinical trial reveal that the association of turbinectomy with septoplasty, though widespread, does not improve the nasal obstruction clinical outcomes and can add risks to patients [15].
Therewithal an objective standardized tool that links anatomy measures with clinical results is not available yet [16]. To address this issue, Stewart et al. have developed and validated the Nasal Obstruction Symptom Evaluation (NOSE) scale, a disease specific QOL instrument designed to determine the presence of nasal obstruction [17]. Since then, several studies have compared preoperative versus postoperative NOSE scores to assess QOL associated with nasal obstruction. A recent survey by the American Society of Plastic Surgeons shows that $90 \%$ of surgeons address the inferior turbinate in at least a portion of their cases, with $8 \%$ routinely reducing the turbinate in all cases. However, $10 \%$ of the respondents in this survey did not address the inferior turbinate in any of their cases [18]. Such variability in addressing this potential cause of/risk factor for nasal obstruction deserves closer attention. Guyuron [19] has pointed out that the position of the inferior turbinates contributes to airway narrowing after nasal bone osteotomy. On account of that, surgical treatment of inferior turbinates seems to be a good option to avoid postoperative nasal obstruction, which would be great because of the accessibility, simple technique and relative low risks. Unfortunately, all three latest trials could not prove any improvement in QOL when the turbinate reduction is associated even by using different techniques. 
Furthermore, to access the turbinate does not seem to improve the rates of nasal obstruction and satisfaction with respiratory scales outcomes [20-22].

In 2013, Lavinsky-Wolff et al. [20] compared QOL in patients undergoing primary Rhinoseptoplasty, with or without turbinate reduction by submucosal electrocautery. There was no difference between subjects submitted or not to inferior turbinate reduction in NOSE score (-75\% vs. $-73 \%$; $\mathrm{P}=0.893)$; all WHOQOL-bref score domains ( $\mathrm{P}>0.05)$, NO-VAS $(-88 \%$ vs. $-81 \% ; \mathrm{P}=0.89)$ and acoustic rhinometry recordings $(\mathrm{P}>0.05)$. Besides the literature does not show difference between the techniques, this study receives some critique about the conservative reduction by submucosal electrocautery chosen. In order to answer this question de Moura et al. [21], in 2017, randomized other 50 patients undergoing

Table 1: Source de Moura et al. [21]. primary Rhinoseptoplasty associated with inferior turbinate reduction through endoscopic partial inferior turbinectomy (EPIT) reduction or not. There was no difference between the groups in absolute score changes for NOSE ( -50.5 vs. -47.6 ; $\mathrm{P}=0.723$ ), Rhinoplasty Outcome Evaluation (ROE) (47 vs. 44.8; $\mathrm{P}=0.742$ ), and all (WHOQOL-bref) score domains ( $>0.05$ ) (Table 1$)$. There were no differences between the groups regarding presence of the complications. Surgical duration was higher in the EPIT group (212 minutes \pm 7.8 vs. $159.1 \pm 5$.6; $\mathrm{P}>0.001$ ). Both articles do not present any improvement at short-term outcomes (three months). Nevertheless, a long-term result was needed to reinforce these findings. Wherefore this year Sommer et al. [22] published a clinical Trial with nine months follow up. They randomized patients to perform anterior turbinoplasty or not during septo- or Rhinoseptoplasty.

\begin{tabular}{|c|c|c|c|c|c|c|c|}
\hline \multicolumn{8}{|c|}{ Quality of Life Outcomes in Individuals Undergoing Rhinoseptoplasty With and Without EPIT } \\
\hline & \multicolumn{3}{|c|}{ Rhinoseptoplasty with EPIT } & \multicolumn{4}{|c|}{ Rhinoseptoplasty without EPIT } \\
\hline & $\begin{array}{c}\text { Preoperative } \\
\text { Mean }( \pm S D)\end{array}$ & $\begin{array}{c}3 \text { Month } \\
\text { Postoperative } \\
\text { Mean ( } \pm \text { SD) }\end{array}$ & $\Delta$ Mean (CI) & $\begin{array}{c}\text { Preoperative } \\
\text { Mean }( \pm \text { SD) }\end{array}$ & $\begin{array}{c}3 \text { Month } \\
\text { Postoperative } \\
\text { Mean }( \pm \text { SD) }\end{array}$ & $\Delta$ Mean (CI) & P value \\
\hline Nose -p & $69.2(25.6)$ & $21.3(20.1)$ & $-50.5(-62.9 ;-.8 .0)$ & $80.2(13.6)$ & $23.4(25.8)$ & $\begin{array}{c}-47.6(-62.3 \\
-32.9)\end{array}$ & $0.723^{*}$ \\
\hline $\begin{array}{l}\text { ROE WHOQOL- } \\
\text { bref domains }\end{array}$ & $28.2(15.2)$ & $68.8(20.8)$ & $47(36.8 ; 57.3)$ & $22.5(17)$ & $69.7(20)$ & $44.8(32.7 ; 57)$ & $0.742 \dagger$ \\
\hline Physical & $63.1(18.7)$ & $67.5(20.04)$ & $6.2(-1.6 ; 14)$ & $65.6(12.9)$ & $76.6(14.6)$ & $11(2 ; 20.2)$ & $0.342 \ddagger$ \\
\hline Psychological & $66.4(15)$ & 71 (13.6) & $6.9(1.3 ; 12.6)$ & $66.3(13.2)$ & $74.9(12.4)$ & $8.8(2 ; 15.6)$ & $0.617 \ddagger$ \\
\hline Social & 69.7 (17.3) & 74.5 (15) & $6.7(-1.3 ; 14.7)$ & $72.6(18.7)$ & 78.8 (19.2) & $9(-0.6 ; 18.6)$ & $0.666 \neq$ \\
\hline Environment & $57.6(11.3)$ & $65.6(13.7)$ & $8.4(1.7 ; 15.1)$ & $61.2(15)$ & $63.7(17.1)$ & $2.6(-5.4 ; 10.5)$ & $0.184 \ddagger$ \\
\hline
\end{tabular}

Dependent variable $\Delta$ scores $=$ (postoperative score-preoperative score)

*P Value: ANCOVA of $\Delta$ adjusted for baseline NOSE - $p$ value, nasal itching, rhinorrhea and use of spreader graft.

†P Value: ANCOVA of $\triangle$ adjusted for baseline ROE score, nasal itching, rhinorrhea and use of spreader graft.

*P Value: ANCOVA of $\Delta$ adjusted for baseline WHOQOL -bref score, nasal itching, rhinorrhea and use of spreader graft.

ANCOVA: analysis of covariance; CI: Confidence Interval; EPIT: Endoscopic Partial Inferior Turbinectomy; NOSE-p: Nasal Obstruction Symptom Evaluation Portuguese; ROE: Rhinoplasty Outcome Evaluation; SD: Standard Deviation; WHOQOL-bref: World Health Organization Quality of Life Scale

The results enhanced previous trials. Patient satisfaction after functional septo- and septorhinoplasty is high and does not seem to be affected by turbinate surgery. There was no statistically significant difference in the postoperative results regarding objective rhinological measurements with or without turbinoplasty (Table 2). They concluded that extensive resections of the turbinates can have a negative impact on nasal physiology, so the indication for turbinoplasty must be carefully considered. Considering these results, clearly has no reason to proceed a turbinate reduction, at least as routine, to patients submitted at rhinoplasty. As medical science is not so hard, presumably some phenotypes of noses probably could benefit of it. Although these patients are not identified, at least it can be justifying by other reasons, this turbinate access should be avoided. This finding changes the focus of discussion to which method should be used to reduce the turbinate to there are another surgical strategy that could be used to improve our functional results and which technique is it. Be like these finds fortify positively the discussion about structured Rhinoplasty and the importance of the reconstruction and reinforce of the nasal valve.

Table 2: Changes in MCA2.

\begin{tabular}{|c|c|c|}
\hline \multicolumn{3}{|c|}{$\begin{array}{c}\text { Acoustic Rhinometry: Changes in Mca2 (Deviated Side of The } \\
\text { Septum) }\end{array}$} \\
\hline \multirow{3}{*}{ Average } \\
\hline \multirow{2}{*}{ No TPL } & Preoperative & $0.30 \mathrm{~cm}^{2}$ \\
\cline { 2 - 3 } & Postoperative & $083 \mathrm{~cm}^{2}$ \\
\hline \multirow{2}{*}{ TPL } & Preoperative & $0.25 \mathrm{~cm}^{2}$ \\
\cline { 2 - 3 } & Postoperative & $0.91 \mathrm{~cm}^{2}$ \\
\hline
\end{tabular}




\section{Conclusion}

The indications for the reduction of the turbinate were well established in context of a turbinate inferior hypertrophy [23,24]. The studies have not shown, until now, a superior technique for the inferior reduction. Although techniques which preserve mucosa and have partial resection instead of total resection are indicated [10-12]. Trends in Rhinoplasty research do not show relevant benefits at patients' quality of life outcomes associated with nasal obstruction when Rhinoplasty is performed combined with reduction turbinate. More clinical trial must be develop comparing other methods of enlargement and preservation of nasal valve and objective measurement instruments need to be developed to clarify these findings [25] (Table 3).

Table 3: Pre-and Postoperative values of the SNOT $20 \mathrm{GAV}$ questionnaire within the groups (TPL vs. No TPL).

\begin{tabular}{|c|c|c|}
\hline \multicolumn{3}{|c|}{ SNOT 20 GAV Questionnaire } \\
\hline \multicolumn{3}{|c|}{ Total Score (Average) } \\
\hline \multirow{3}{*}{ No TPL } & Preoperative & $26 / 100$ \\
\cline { 2 - 3 } & Postoperative & $16 / 100$ \\
\hline \multirow{2}{*}{ TPL } & Preoperative & $30 / 100$ \\
\cline { 2 - 3 } & Postoperative & $16 / 100$ \\
\hline
\end{tabular}

\section{References}

1. Christophel JJ, Park SS (2009) Complications in Rhinoplasty. Facial Plastic Surgery Clinics of North America 17: 145-156.

2. Constantian MB, Clardy RB (1996) The relative importance of septal and nasal valvular surgery in correcting airway obstruction in primary and secondary rhinoplasty. Plast Reconstr Surg 98(1): 38-54.

3. Becker DG, Ransom E, Guy C, Bloom J (2010) Surgical Treatment of Nasal Obstruction in Rhinoplasty. Aesthetic Surg J 30(3): 347-378.

4. Wulkan M (2012) Comparative study in cadavers of the use of septal and costal cartilaginous grafts to increase the external sectional area of the thesis presented to the Faculty of Medicine of the University of São Paulo to obtain the title of Doctor in. PhD thesis, Brazil.

5. Tasca I, Ceroni Compadretti G, Sorace F (2013) Nasal valve surgery. Acta Otorhinolaryngol Ital 33(3): 196-201.

6. Surowitz JB, Most SP (2013) Complications of Rhinoplasty. Facial Plast Surg Clin NA 21(4): 639-651.

7. Batra PS, Seiden AM, Smith TL (2009) Surgical management of adult inferior turbinate hypertrophy: a systematic review of the evidence. Laryngoscope 119(9): 1819-1827.

8. Leong SC, Eccles R (2010) Inferior turbinate surgery and nasal airflow: evidence-based management. Curr Opin Otolaryngol Head Neck Surg 18(1): 54-59.

9. Omranifard M, Adib M, Ebrahimpour S (2019) Comparative Study of the Effectiveness of sub mucosal Partial Inferior Turbinectomy and Out fracture of Inferior Turbinate in the Nasal Respiratory Function of Rhinoplasty Patients. Aesthetic Plast Surg 43(5): 1281-1285.

10. Passali D, Passali F, Passali G, Damiani V, Belussi L (2003) Treatmeant of Inferior Turbinate Hypertrophy: A randomized Clinical Trial. Ann Otol Rhinol Laryngol 112(8): 683-688.
11. Stölzel K, Bandelier M, Szczepek AJ, Dommerich S (2017) Effects of surgical treatment of hypertrophic turbinates on the nasal obstruction and the quality of life. Am J Otolaryngol 38(6): 668-672.

12. Veit JA, Nordmann M, Dietz B, Sommer F, Rotter N, Greve J, et al. (2016) Three Different Turbinoplasty Techniques Combined with Septoplasty : Prospective Randomized Trial. Laryngoscope 127(2): 303-308.

13. Rodrigues MM, Dibbern RS, Oliveira LF De, Dirce M, Marques O, Bella $\mathrm{MF}$, et al. (2011) Comparison between turbinoplasty and endoscopic turbinectomy : Efficacy and clinical parameters Comparação entre turbinoplastia e turbinectomia endoscópicas : Eficácia e parâmetros clínicos. Arq Int Otorrinolaringol pp. 426-430.

14. Clement WA, White PS (2001) Trends in turbinate surgery literature: a 35-year review. Clin Otolaryngol Allied Sci 26(2): 124-128.

15. Egmond MMHT Van, Rovers MM, Hannink G, Hendriks CTM, Heerbeek N Van (2019) Septoplasty with or without concurrent turbinate surgery versus non-surgical management for nasal obstruction in adults with a deviated septum : a pragmatic, randomised controlled trial. Lancet 6736(19): 1-8.

16. Rhee JS, Poetker DM, Smith TL, Bustillo A, Burzynski M, et al. (2005) Nasal valve surgery improves disease-specific quality of life. Laryngoscope 115(3): 437-440.

17. Stewart MG, Witsell DL, Smith TL (2004) Development and validation of the Nasal Obstruction Symptom Evaluation (NOSE) Scale. Otolaryngology- Head and Neck Surgery 130(2): 157-163.

18. Afifi AM, Kempton SJ, Gordon CR, Pryor L, Khalil AA., et al. (2015) Evaluating Current Functional Airway Surgery During Rhinoplasty: A Survey of the American Society of Plastic Surgeons. Aesthetic Plast Surg 39(2): 181-190.

19. Guyuron B (1998) Nasal osteotomy and airway changes. Plast Reconstr Surg 102(3): 856-860.

20. Lavinsky M, Camargo HL, Barone CR, Rabaioli L, Wolff FH, et al. (2013) Effect of turbinate surgery in rhinoseptoplasty on quality-oflife and acoustic rhinometry outcomes: A randomized clinical trial. Laryngoscope123(1): 82-89.

21. Moura BH De, Migliavacca RO, Lima RK, Brauwers E (2017) Partial Inferior Turbinectomy in Rhinoseptoplasty Has No Effect in Qualityof-Life Outcomes : A Randomized Clinical Trial. Laryngoscope 128(1): 57-63.

22. Sommer F, Scheithauer MO, Hoffmann TK, Grossi A, Hauck K, Lindemann J (2019) Value of turbinoplasty in rhinosurgery - a controlled randomized study. Rhinology 57(5): 352-357.

23. Han JK, Stringer SP, Rosenfeld RM, Archer SM, Baker DP, et al. (2015) Clinical Consensus Statement: Septoplasty with or without Inferior Turbinate Reduction. Otolaryngol Head Neck Surg 153(5): 708-720.

24. Karlsson TR, Shakeel M, Supriya M, Ram B, Ah See KW (2015) Septoplasty with concomitant inferior turbinate reduction reduces the need for revision procedure. Rhinology 53(1): 59-65.

25. Burgos MA, Sevilla A, Rojas S, Pino C Del, Velez F, Piqueras F, et al. (2018) Virtual Surgery for Patients with Nasal Obstruction : Use of Computational Fluid Dynamics ( MeComLand, Digbody \& Noseland ) to Document Objective Flow Parameters and Optimise Surgical Results. Acta Otorrinolaringol 69(3): 125-133. 
(c) (i) This work is licensed under Creative

To Submit Your Article Click Here: Submit Article

DOI: $10.32474 /$ SJ0.2020.04.000176

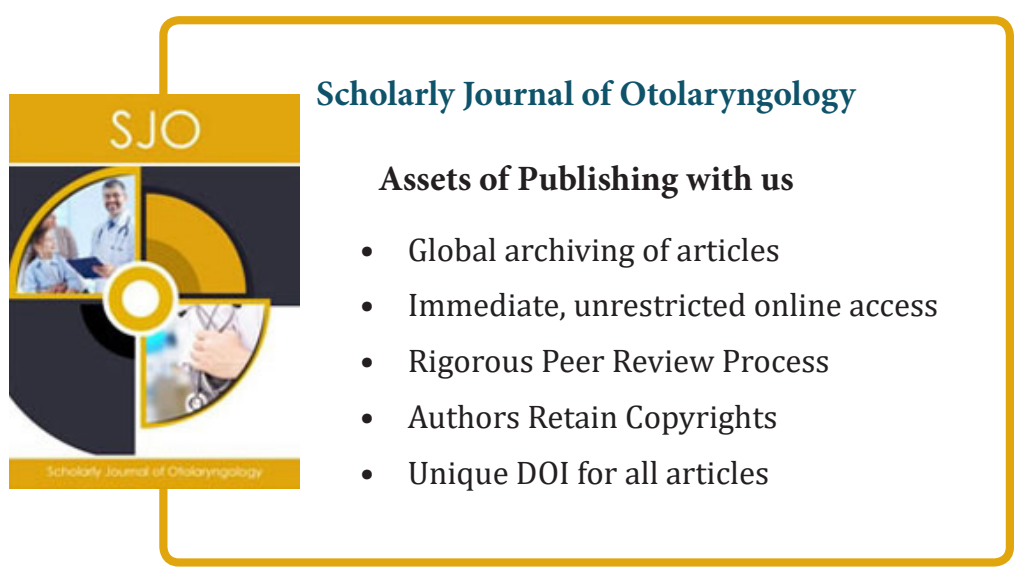

